\title{
Clause Structure and Word Order in Ákè
}

\author{
Waheed Ayisa Jayeola \\ http://dx.doi./org/10.4314/ujah.v22i1.5
}

\begin{abstract}
Ákè is by historical and linguistic facts a dialect of Edo which has not received significant linguistic attention. This neglect informs an inquiry into the in ternal structure and organization of its basic clause. This paper studies data of everyday usage of competent speakers of Ákè and argues that it displays a subject-verb-object order. The study provides a not too elaborate description of the nominal and verbal constructions in Ákè and reduces the description to analysis using the $\mathrm{X}$-bar theory as conceived within the Minimalist Program. It therefore states that nominal phrases can be analysed as a projection of Determiner Phrase (DP) because independent existence is not a requirement for considering an element as the head of a projection. The variable position which the head D occupies in the superficial syntax of Ákè is analysed as the effect of movement for feature checking. In the spirit of the Minimalist Program, this study recognizes the head of the clause as Tense (T), which could be overt or null and predicts that it dominates Negative Phrase (NegP) as Neg is assumed to c-select the Verb Phrase (VP).
\end{abstract}

\section{Keywords: Ákè, tense phrase, clause, null-head, minimalist program}




\section{Introduction}

Ákè is the name of the speech form spoken in Ákè town located in the Owan East Local Government Area of Edo State. Oral tradition of the speakers has it that Ákè people migrated from Benin. This provides explanations for the similarities present in Edo and Ákè. According to Alarape (2017), geographically, Ákè is surrounded in the South East by Uokha, in the North by Otuo, East by Igue and West by Arokho. He also reports that there is little documentation about the grammar of Ákè, hence the need to take up the present study.

The thrust of this paper is to investigate the structure of the basic clause in Ákè by discussing the features of the elements that make up the clause and show how the elements are ordered relative to one another. The data used for this study indicate that Ákè is somewhat configurational, making it to align with Kayne's (1994) Linear Correspondence Axiom (LCA). However, movement to the left periphery of the clause i.e. CP enables OSV. Contrary to Omoregbe's (2014) claim, this study shows that nominal projections in Ákè, a dialect of Edo, are amenable to the DP analysis. The study will further state that verbs in Ákè always keep the same forms even though at LF they are specified for present/past or for future.

\section{Basic Constituents of Ákè Clause}

According to Carnie (2007:72) a clause consists of a subject, traditionally analysed as the Noun Phrase and a VP, whereas the clause itself, in tune with X-bar theory, is a projection of TP. The subject is a doer, an agent and the predicate describes the subject. These elements are regarded as universal to all languages. First, a 
descriptive account of these elements in Ákè is provided; the description will be reduced to theoretical analysis later.

\section{The Noun Phrase}

Traditionally, a Noun Phrase (NP) has the noun as its head, or simply a pronoun when it is not modified. This implies that a noun can occur independently or with qualifiers in the nominal group. In (1a) the two arguments in the sentence; subject and object are nouns without any modifier. In (b) however, a pronoun in the subject position functions as the head of the noun phrase.

1a. Àhólé dé ìmótò

Ahole buy car

'Ahole bought a car'

c. I gbé néwé

1 sg kill goat

'I killed a goat'

On the other hand, the head noun in a noun phrase may take optional modifiers i.e. determiner and adjective.

2a. òní ómóhè

Def man

'The man'

b. òní èmíèmí

Def lizard

'The lizard'

In (2), the item òní functions as a kind of modifier that makes specific reference to the noun it is associated with. Linearly, it occurs before the noun. It appears that Ákè does not have a distinct marker for indefiniteness; it instead makes use of number as shown by the example below. 
3a. òhá òkpá

house one

'A/one house'

Unlike the definite marker, number as a modifier of the noun occurs after the noun it modifies. This is the case with (3b) where number consistently comes after the noun.

b. ìkóókpù ìgbévá

cup twelve

'Twelve cups'

Another set of modifiers found in Ake is quantifier, which Matthews (1997:305) describes as any word or expression that gives relative or indefinite indication of quantity.

4a. òhá nòbúbú

house many

'Many houses'

b. ìfúláwà èsó

flower some

'Some flowers'

Similar to the behaviour of numeral, when quantifiers are used as modifiers of nouns, they occur in post nominal position.

The internal structure of the NP in Ákè indicates that one noun can modify another noun to produce what Owolabi (1976) describes as a Noun-Noun construction. This kind of constructions normally shows a relation of possessor and the possessed item. However, the NP analysis does not specify the location of the head of the phrase. This is shown below.

5a. òhá sí ìrámé

house of father

'Father's house/house of father' 
b. ìmótò sí Àjòlò

motor car of Àjòlò

‘Àjòlò's car/car of Àjòlò

In a not too different fashion, it is possible to have noun-possessive pronoun constructions. In this case, the possessive pronoun expresses the notion of ownership and is assumed to function as a modifier to the head noun.

6a. úmì màì

head 1Pl.poss

'Our heads

b. óvbì óì

child 3Sg.poss

'His/her child'

One other category that is found within the NP of Ákè is known as distributive determiner. This particle refers to each member of a class separately. Its morphological form is rémè, meaning 'every'.

7a. úkì rémè

month every

'Every month'

b. ùkpèdè rémè

day every

'Every day'

It is clear from the data above that rémè 'every' is morphologically independent and consistently post-modifies the head NP. Semantically, rémè as a distributive determiner only encodes singularity.

Cross linguistically, adjective is another class of noun modifier. Hurford (1994:8) sees adjective as "a word typically used to modify a noun and which describes the property of the thing 
referred to by the noun". Items that appear to fit into the description which Hurford provides for adjective include the ones below.

8a. ómòhè nòbì man black

'(a) black man'

b. òhá nógbórè house new

'(a) new house'

c. òní òhá nógbórè

Def house new

'The new house'

d. ìmótò eva níkéré

motor car two small

'Two small cars'

The items in bold face are interpreted as adjectives within the noun phrase. They are consistently post nominal and adjacent to the noun they modify when no other modifier occurs within the noun phrase or a definite determiner is found which on its part occurs before the noun. However, when another modifier like numeral is present, the linear order is altered making the numeral closer to the head noun than the adjective example (d). There are arguments concerning the status of adjectives in most African languages but this study, for lack of space will not delve into them at the moment. Nonetheless, a comparison of the data in (5) with those in (8) favours the recognition of the bold faced items in (8) as adjectives.

So far, we have seen how NPs in Ákè can be hierarchically organized with respect to its satellites. The analysis puts determiners like òní 'the', òkpá 'one', nòbúbú 'many', rémè 'every' in the specifiers of NPs. The position of these items relative 
to the head $\mathrm{N}$ is not consistent. It is mixed headedness for NPs; the head noun can precede or follow its specifiers, same as what Omoregbe (2014) mentions about Edo. This situation manifests a directionality parameter which in the spirit of Kayne's (1994) universal specifier-head-complement hypothesis is no longer desirable. Setting that apart, the NP analysis seems incapable of showing what the head of genitive NPs in (5) should be. Thus, the next section shall discuss the NPs in the light of the DP hypothesis.

\section{Ákè NPs and the DP-Hypothesis}

The treatment of determiners in the previous section as the specifiers of NPs violates one of the basic principles underlying Xbar theory: All non-head material must be phrasal; this idea, conceived within the Modifier Maximality Constraint (Stowell, 1981:70 in Radford 1988:263), does not support the generation of determiner elements in Spec-NP. By this constraint, determiners are heads; it however does not reduce or remove the fact that $\mathrm{N}$ can potentially project maximally. Nevertheless, Omoregbe (2014:259) argues that the DP-Hypothesis is not capable of handling the situation in Edo, a language with which Ákè shares close and strong relationship, because the elements identified as determiners in the language do not occur independently of NPs. The position of this paper is that independent occurrence is not a requirement in the postulation of the DP-Hypothesis. In fact, cross linguistically there are some count nouns that cannot stand on their own as complete noun expressions (cf. Radford 1997: 40). The basic assumption in the formulation of the DP-hypothesis Abney (1987) is that the determiner is not actually inside the NP; it rather heads its own phrasal projection. 
Furthermore, the DP-hypothesis predicts that there is an intricate relationship between nouns and determiners which is based on functional agreement. The grammatical agreement properties of person, number and/or gender (technically known as Phi-features), Burchfield (1996: 629), Radford et al (2009) must be shared between two items. This is the case with the examples below where there is number agreement (plural) between the definite determiner and its noun complement.

9a. èní ívbìe

Def.Pl child.Pl

'The children'

b. èní ímòhé

Def.Pl man.Pl

'The men'

The data in (9) support one major view of the DP-Hypothesis which speculates that the determiner lexically instantiates the functional agreement that selects the noun as its complement. The expressions below are ill-formed because there is a mismatch of features between the two items.

c. *òní ímòhé Def.sg man.PL

d. *èní ómòhé

Def.Pl man.sg

Examples (9a-d) clearly point to the existence of number agreement (singular) though not morphologically marked between a singular definite determiner and a singular noun, example (2) above repeated here as (9e-f).

9e. òní ómóhè

Def man 


\section{'The man' \\ f. òní èmíèmí \\ Def lizard \\ 'The lizard'}

Apart from the issue of agreement, the definite determiner in the above syntactic derivations determines the referential properties of the noun expression which comes after it. Another referential determiner is the possessive pronoun, which in overt syntax is post nominal.

10a. úmì màì

head 1Pl.poss

'Our heads'

b. óvbì óì

child 3Sg.poss

'His/her child'

The semantic scope of the possessive pronoun in (10) confers the head of the projection on it. The same analysis suffices for Numeral in (3), Quantifier in (4) and Distributive in (7). Each of these subtypes of determiner provides the appropriate scope for the interpretation of their respective NP complements.

Also, this study takes bare nouns i.e. Àhólé, Àdógà, Sámúènì which are examples of proper names as instantiations of $\mathrm{D}$ because they are elements that occupy argument positions. Bare nouns/personal names are devoid of any modifying element whereas a very popular view on minimalist ideas predicts that reference feature is associated with D. Interestingly, proper names as used in (11) are interpreted as referential expressions (cf. Chomsky 1993, Pereltsvaig 2007), thus, they maximally project DP which is headed by a null determiner.

11a. Àhólé dè ìmótò 
A buy car

'Àhólé bought a car'

b. Àdógà gbé Sámúènì

Àdógà kill Samuel

'Àdógà killed Samuel'

Cross linguistically, personal pronouns do function the same way as do noun phrases. In Ákè as well, they can occupy subject and object positions. Unlike nouns however, pronouns same as determiner elements are treated as functors because they lack intrinsic descriptive content of their own. The pronouns in (12) obviously lack independent referents and their antecedents are unknown.

$12 \mathrm{a}$
Ó mí èmí
$3 \mathrm{sg}$ see $1 \mathrm{sg}$
'S/he saw me'
$1 \mathrm{pl}$ Fut see 3pl
'We will see them'

b. màì nè mí àrín

The personal pronouns in (12) require context for their interpretation thus, Radford (1997:40) describes them as a subtype of determiners that can be used on their own. Other studies take them as deictic which can be described as intransitive determiners (see Postal 1966, Abney 1987, Cardinaletti 1994, Ritter 1995, Noguchi 1997).

Another piece of empirical evidence in favour of treating $\mathrm{NP}$ as the complement to the determiner head comes from the behaviour of genitive (possessive) NPs. Of the two categories of genitive identified in the literature: free genitive or of-genitive and construct or 's-genitive (cf. Carnie 2007:197-8), this study 
identifies the free genitive or of-genitive in Ákè. The free genitive in this case uses the particle si to mark or express the possessive relation between the two NPs which do not share the same referent.

13a. Òhá sí ìrámé

House of father

'Father's house/house of father'

b. ìmótò sí Àdívé

motor car of Àdívé

'Àdívé's car/car of Àdívé'

The data in (13) show relations of possessor and the possessed which are lexical nouns; the possessed precedes the possessor with an overt item intervening between them. Nkemnji (1995) describes this particle as an "Associative Marker". In line with the DP-hypothesis (Abney 1987) and the minimalist assumption (Chomsky 1995), this study considers the kind of structures in (13) as an instantiation of D. Sí is assumed to carry an interpretable D-feature (specific semantic property) which is a marker of possession.

Having recognised si as the head of the DP-possessive, the proposal follows that the DP-possessive in Ákè establishes a structural relationship between two non-identical entities that are selected by a functional possessive head that intervenes between them.

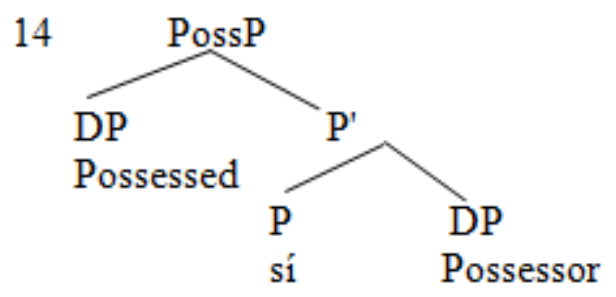


The structure in (14) follows from the analysis of bare nouns as a projection of DP. In (14) the possessed DP appears in the specifier of what has been designated as Possessor Phrase (PossP) headed by sí while the DP with the possessor value occurs as the complement. The account here follows from Kayne's (1994) co-argument relation analysis where his proposed universal linear order of head and its satellites - S-H-C is satisfied. The choice of PossP in this study as against DP bears directly on the relevance of the Split-DHypothesis assumed in Aboh (2004, 2013).

Except for the definite determiner and the genitive construction just analysed, other sub-classes of D such as Numeral, Quantifier, Distributive and Pronominal Possessive in Ákè occur post nominally. This apparent superficial variation is a violation of the LCA requirement which opposes the notion of head parameters. The proposal in this study is that the NPs raise from the complement positions of their respective heads to check their features as appropriate at the specifier positions of their respective heads. The movement is feature induced; otherwise the derivations will crash.

\section{The Verb Phrase}

The other important constituent of the clause found in languages is the category headed by the verb: the verb phrase (VP). As it is with other languages, a VP in Ákè minimally consists of a single verb. This is the case of intransitives:

15a. Àdívé méhè 
Àdívé sleep

'Àdívé slept'

b. Ó nè vbàré

3sg Fut come

'S/he will come'

Apart from what is illustrated above; there is a subcategory of verbs that can take an NP object. This is the case of transitive verbs where these NPs appear immediately after the V. Consider the following examples.

16a. James dè ìmótò

James buy motor car

'James bought a (motor) car'

b. Ó mí Àdívé

3sg see Àdívé

'S/he saw Àdívé'

Examples in (15-16) express some amount of taxonomy in the nature of the verbs. Transitive verbs by their nature require a complement because the action expressed by a verb is construed as passing directly from the subject to its complement whereas intransitives are not complement taking verbs. The VP in Ákè is strictly head-initial making it possible for it to be analysed within the X-bar framework. The structure of the verbs in (16) clearly fits into the head-complement order. The situation in (15) is the one in which the verb merges with a null-complement to project maximally to VP.

\section{Word order in Ákè}

One very important feature of natural languages is in relation to the basic syntactic structure of declarative sentences. Essentially, the focus is always on the positions of subject, verb and object relative 
to each other. It is sometimes difficult to determine what a neutral word order is in a language because languages often use different word orders in virtually the same type of constructions; a language may tolerate more than one word order within a declarative sentence. Also, it is possible for languages to use different word orders in different types of constructions i.e. questions versus declarative statements; main clauses versus embedded clauses. One popular diagnostic in the determination of default or canonical word order is the use of sentences in which all information is equally new. The following example sentences below will help situate Ákè into a word order typology.

16a. Àdívé dè ónebè

Àdívé buy book

'Àdívé bought a book'

b. Ó ho úkpò

3sg wash cloth

'S/he washed clothes'

The two sentences in (16) provide new information and indicate subject-verb-object word order typology. This shows that in a simple transitive sentence of Ákè the subject nominal appears before the verb and the object nominal occurs after and is adjacent to the verb. The same condition applies when the verb in the declarative expression is intransitive.

17a. É góì

$3 \mathrm{pl}$ cry/weep

'They cried/wept'

b. Òní ómóhè nè vbàré

Def.sg man.sg Fut come

'The man will come' 
The order found in (17b) where the particle nè glossed as future marker stands between the subject DP which is the agent and the intransitive verb vbàré 'come' does not matter.

As contained in popular literature on word order, the positions which adjunct elements like adverbial or locative/instrumental phrases occupy are also crucial in the configuration of basic word order. For instance, when a piece of information that is new is given, the category adjunct in Ákè basic clause occurs after the verb adjacent to the nominal object.

18a. Àdáòbì nè mí Àdógà vbí ékì Àdáòbì Fut see Adoga $\mathrm{P}$ market 'Àdáòbì will see Adoga at the market place'

b. Àhólé wí ìmótò nógbórè vbí Lóndònì Àhólé bring car new $P$ London 'Àhólé brought a new car from London

The category adjuncts in (18) which all appear in bold face are post verbal; they do not affect the subject-verb-object order assumed for Ákè.

There is evidence to suggest that Ákè makes use of a noncanonical word order in non-neutral contexts i.e. question and focus as in (19).

19a. $\grave{E}_{\mathrm{x}}$ nè ú dè $t_{x}$

What Fut 2sg buy

'What will you buy'

b. İyésìx İmúsá éì $t_{x}$

rice İmúsá eat

'İmúsá ate RICE

A cursory look at the glosses of the sentences above indicates that they do not provide new information. They naturally 
do not fall into the category of expressions that can ordinarily be used to begin a conversation. Thus, they are assumed to be derived via movement of elements from their canonical position to a surface position for the purpose of showing one or another discourse effect. For instance example (19a) is assumed to be a content question where the object NP of the verb buy is being questioned. It is the case that the object NP originates at a post verbal position marked as $t_{x}$ which has to wind up at the sentence initial position as an interrogative pronoun because it does not allow the Wh-item to remain in-situ. Similarly, example (19b) is not considered as a basic sentence. An emphasis is placed on a particular element within the clause and the grammatical requirement for the realisation of such discourse effect is to move the emphasised element out of its original position to the sentence initial position.

In the two instances above, the nominal objects of their respective verbs are found in the sentence initial position Spec-CP to yield an Object, Subject and Verb order. This kind of order is marked.

\section{The Structure of the Clause}

Now that the structures of the major constituents of the sentence have been considered and their linear order relative to one another are stated; the next step is to look at how the basic clause is formed. On the basis of the adoption of the X-bar theory, the head of the clause as earlier hinted is a $\mathrm{T}$ (tense) that maximally projects to give a TP (tense phrase). This assumption produces the structure below: 


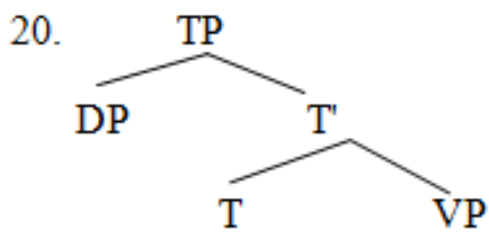

The schema above derives from the position that Ákè displays an SVO order. By that arrangement, the subject DP occupies the specifier of TP while the VP is the complement. The specifier here corresponds to the subject of the clause. At a glance, the head of the phrase (T) is apparently not overt. It would seem that the tree adequately handles the sentences in (21) because each of them has a DP that corresponds to the subject and the VP that stands in complement relation to the head $\mathrm{T}$.

21a. James dè ìmótò

James buy motor car

'James buys/bought cars/a car'

b. Ádá hòmèkèì ìyó óì

Ada love mother 3Sg.poss

'Ada loves/loved her mother'

However, the interpretation provided for the sentence suggests that tense (present/past) which does not have phonological representation in Ákè actually merges with the VP to project a T'. The correctness of this prediction is borne by the sentence in (22).

22. máì nè mí àrín

1 pl Fut see 3pl

'We will see them'

The presence of the particle nè interpreted as the future tense marker attests to the prediction that the $\mathrm{T}$ node may be lexically filled or may be covert. From the foregoing it is obvious that verbs in this case do not inflect for tense and that Ákè allows for a future 
marker only. Following from the interpretations of the data in (2122 ), it is suggested that the temporal specifications for present/past are derived from the expression of a null morpheme that encodes the feature [-future]

As plausible as the analysis appears, it runs into an immediate problem the moment the truth-value of the propositional contents of the kind of sentences in (21) are reversed.

23. Sámúènì oi hò úkpò

Sámúènì Neg wash cloth

'Sámúènì does/did not wash clothes'

The data in (23) shows that tense and negation are fused together; the two categories produce one indivisible item that consistently precedes the verb. To treat the negative marker as a part of the $\mathrm{T}$ category will not be consistent with the headedness requirement. One way round the problem is to explore an analysis that introduces a functional phrase along the clausal spine. The feasibility of this proposal relies on the fact that the negative particle found in (23) is not an affix and should be considered as a negative marker that is qualified to head a NegP (cf. Zeijlstra 2013:11). Having recognised NegP, the next step is situating it within the clausal spine. Without much ado, the data in this paper neatly subscribes to Ouhalla's (1991:138) NEG parameter I (i) where NEG c-selects VP. In line with this account, Ákè data shows that Neg c-selects for VP because it dominates and asymmetrically C-commands the VP as captured in the structure below. 


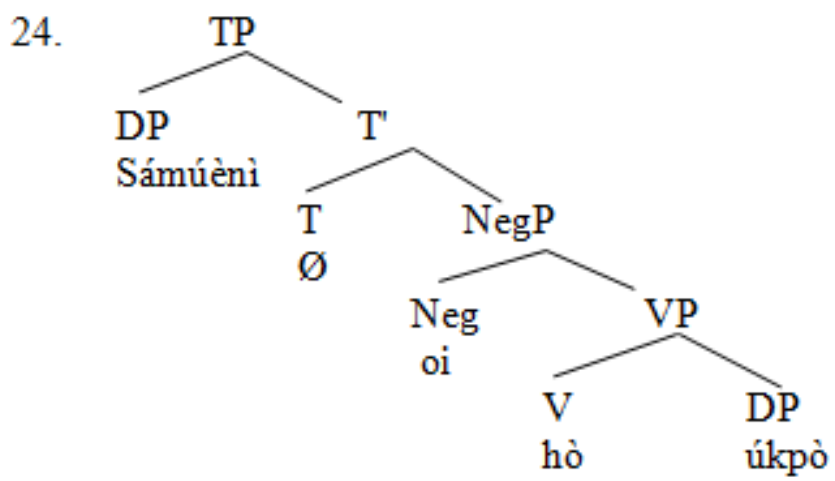

Based on the interpretation of the structure in (24), Neg is assumed to raise to Tense in compliance with Head adjunction to account for morphology in syntax. Besides, the negative marker is bound to associate with the Tense head to meet the principle of Full Interpretation, which obligatorily demands that all the features of a pair must be legible at the relevant interfaces. This tree succinctly takes care of the structure in (23). It shows that Ákè combines in the particle $o i$ tense and negation.

What is presented in (24) appears to be defective in terms of exploring the structure of the basic clause of Ake. It has not accommodated the peculiarity of the example in (19b) repeated here as (25).

$$
\begin{aligned}
& \text { 25. İyésìn İmúsá éì } t_{\mathrm{x}} \\
& \text { rice İmúsá eat } \\
& \text { 'İmúsá ate RICE' }
\end{aligned}
$$

In (25), a part of the clause, precisely the internal argument is focused; it provides the most relevant or most salient information in the given discourse situation. This is achieved by raising the verb complement iyesi 'rice' to the clause initial position. One 
immediate syntactic implication of this is the introduction of a change into the word order. According to Rizzi (1997), Complementizer Phrase (CP) as conceived within GovernmentBinding approach is the projection that houses a phrase head at the left periphery of the clause. Based on the discourse effect of the movement observed in (25), this paper adopts the Split-CP Hypothesis (cf. Chomsky 1995; Rizzi 1997) and recognizes the landing site of the moved item as the specifier position of Focus Phrase (FocP) proposed by Awoyale (1995). This is not to say that every instance of movement to the overall sentence initial position is a FocP. Depending on what moves and what triggers it; other materials can appear on the left edge or the CP domain/layer of the sentence (cf. Rizzi 1997:288, Aboh 2004:47). On the strength of the foregoing argument, the clause structure of Ákè is illustrated in (26).

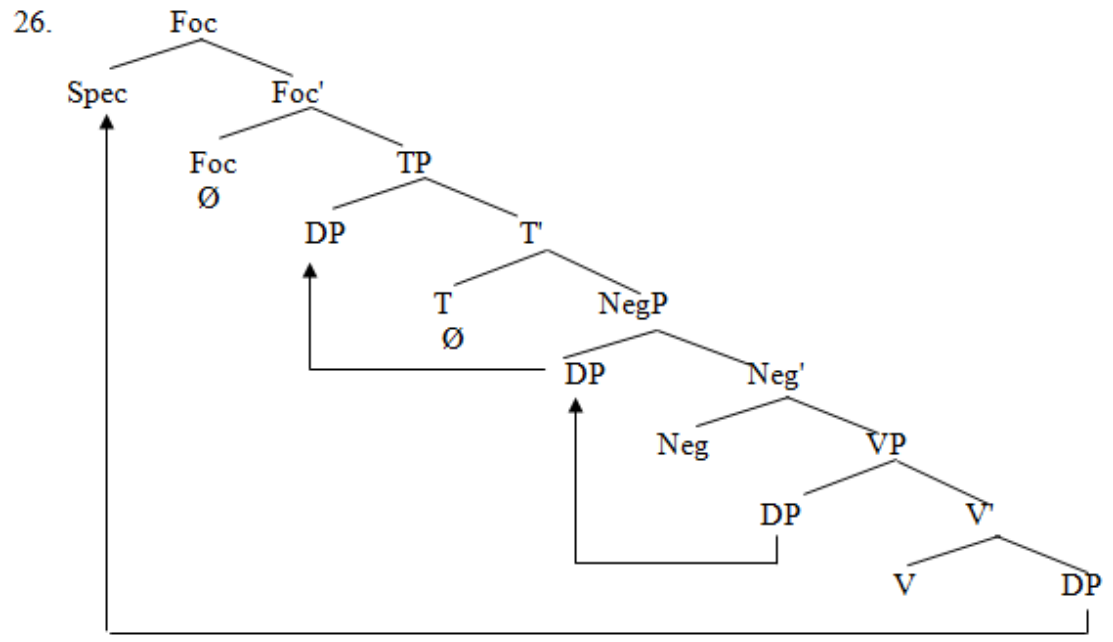


The tree shows the dominance and precedence relations in the clause structure. The verb externally merges with its DP complement to form a V' which in turn merges with the DP subject to project the VP. The derivation progresses and terminates with the FocP (CP). In line with the Predicate Internal Subject Hypothesis, the subject DP originates at the Spec-VP and winds up at the Spec-TP to check its Nominative case. The leftward movement of the focused element to a position left adjacent to a null focus marker is an instance of internal merge where the internal argument is associated with two syntactic positions. Adebiyi (2017:54) suggests that Ákè does not use or mark focus. However, this study assumes that Ákè combines syntactic and prosodic means to mark focus which is signaled in discourse through intonation. The movement of the internal argument to the front of the overall sentence into the Spec-FocP is to satisfy the strong (EPP) feature of the null FocP head. Consequently, a phonetically null copy is left at the extraction site in line with Chomsky's Copy theory of movement.

\section{Conclusion}

This paper has attempted an investigation of the basic clause of Ákè, a dialect of Edo and asserts that it is configurationally SVO. However, there could be a change in the word order to OSV, which is associated with different information structure interpretations for the object. The paper explains that agreement relations in terms of number marking between determiners and their complement noun phrases provide strong evidence for the suitability of the DP hypothesis in the analysis of nominal constructions in Ákè. Particularly striking is the structure of the genitive (possessive) NP which clearly conforms to the Specifier-Head-Complement order 
Jayeola: Clause Structure and Word Order in Ákè...

predicted by Kayne (1994). This study analyses the variability in the surface order or position of a Determiner in relation to its head i.e. complement-head order as the possible effect of feature checking which induces movement. On account of the linear order of constituents within the clause structure, the paper concludes that Tense dominates NegP because Neg c-selects VP and that the two functional categories produce one indivisible item that consistently precedes the verb.

Waheed Ayisa Jayeola

Obafemi Awolowo University, Ile-Ife, Osun State.

jayeolawaheed@yahoo.com 


\section{References}

Abney, S. P. 1987. The English noun phrase in its sentential aspect.

PhD. Dissertation. MIT. 363pp.

Aboh, E. O. 2004. The morphosyntax of complement-head sequences: clause structure and word order patterns in $k w a$. New York: Oxford University Press.

Aboh, E. O. 2013. The morphosyntax of the nominal left periphery. Hand out, African Linguistics School III, Nigeria, July, 2013.

Adebiyi, K. I. 2017. Negation in Ake Dialect. B.A. Long Essay, Department of Linguistics and African Languages, Obafemi Awolowo University, Ile-Ife.

Alarape, I. A. 2017. The Simple Declarative Sentence of Ake. B.A. Long Essay, Department of Linguistics and African Languages, Obafemi Awolowo University, Ile-Ife.

Awoyale, Y. 1995. The role of functional categories in syntax: the Yorùbá case. In K. Owolabi (ed.). Language in Nigeria, 113-128. Ibadan: Group Publishers.

Cardinaletti, A. 1994. On the internal structure of pronominal DPs. The Linguistic Review 11: 91-219.

Chomsky, N. 1993. A minimalist program for linguistic theory. In K. Hale, \& S. J. Keyser (eds.). The View from Building 20: Essays in Linguistics in Honour of Sylvain Bromberger, 152. Cambridge, MA: MIT Press.

Chomsky, N. 1995. The minimalist program. Cambridge, MA: MIT Press.

Hurford, J. R. 1994. Grammar: a students' guide. Cambridge:

C U P.

Kayne, R. S. 1994. The antisymmetry of syntax. Cambridge, Mass. MIT Press. 
Matthews, P. H. 2007. The concise Oxford dictionary of linguistics. $2^{\text {nd }}$ ed. Oxford University Press: Oxford.

Nkemnji, M. A. 1995. Heavy pied-piping in Nweh. PhD. Thesis. UCLA. Los Angeles.

Noguchi, T. 1997. Two types of pronouns and variable binding. Language 73: 770-797.

Omoregbe, E. M. 2014. The Morpho-Syntax of the determiner 'né' and Abney's DP-Hypothesis in Edo Nominal Constructions. Papers in English and Linguistics. The Linguistics Association, Obafemi Awolowo University, Ile-Ife, Nigeria. 15: 254-268.

Ouhalla, J. 1991. Functional categories and parametric variation. Routledge: London and New York.

Owolabi, K. 1976. Noun-noun constructions in Yoruba: a syntactic and semantic analysis. PhD. Thesis. University of Ibadan, Ibadan, Nigeria.

Pereltsvaig, A. 2007. Copular sentence in Russian. Dordrecht. The Netherlands: Springer.

Radford, A. 1997. Syntax: a minimalist introduction. Cambridge: C U P.

Radford, A. Atkinson, M. Britain, D. Clahsen, H. and Spencer, A. (2009). Linguistics: an introduction. $2^{\text {nd }}$ ed. Cambridge:

C U P.

Rizzi, L. 1997. The fine structure of the left periphery. In L. Haegeman (ed.). Elements of Grammar: Handbook in generative syntax. Dordrecht, Netherlands: Kluwer. 281337

Stowell, T. 1981. Origins of Phrase Structure. PhD. Dissertation. MIT. 
Zeijlstra, H. 2013. Negation and Polarity. Hand out, African Linguistics School, Ibadan, Nigeria. 